\title{
A Critcal Study of Driving Performance of Heavy Duty Vehicle Running on Long Downhill Road Using Engine Brake
}

\author{
Xuan Zhao, Xiaolei Yuan* and Qiang Yu \\ School of Automobile, Chang'an University, Xi'an, China
}

\begin{abstract}
For ensuring safety of heavy duty vehicles running on long downhill sections, a model was built for the application of engine brake and service brake combination based on test results. A model of brake temperature rise for heavy duty vehicles running on long downhill sections was also constructed. For different braking modes, gear positions, speed and downhill slopes, brake temperature rising to $250^{\circ} \mathrm{C}$ was used as the index. Then simulation of brake temperature rise and downhill distance was researched. Simulation results illustrate that the combined braking of low gear and high speed should be adopted for heavy duty vehicles running on long downhill sections.
\end{abstract}

Keywords: Brake temperature rise, engine brake, heavy duty vehicles, running on long downhill.

\section{INTRODUCTION}

The implementation of develop-the-west strategy has unfolded emerging opportunities for regional economy. The center of road construction is moving from eastern plains to western mountain areas [1]. Considering cost, environment and natural conditions, standard critical design parameters are strictly followed for designing and constructing roads in steeply sloping mountainous [2-4]. Hence, driving safety on winding and steep mountain roads is one of the most important concerns that needs to be addressed in traffic safety.

When a vehicle moves on downhill roads, gravitational energy translates to kinetic energy, consequently increasing the speed of the vehicle increases. In order to ensure the safety of vehicle, certain brake force is inevitably required to control the speed. However, on long steep downhill distance, the use of brake increases and brake temperature exceeds the margins. It directly affects the brake performance and gradually deteriorates with fast movement of the vehicle [5, 6]. Therefore, while driving on steep downhill roads, continuous brake force is essentially required. Similarly, if continuous brake force fails to meet the need of braking requirements, service brake starts working. For this reason, driving performance with the combination of engine brake and service brake for heavy duty truck has been discussed in this paper.

\section{FUNDAMENTALS OF ENGINE CONTINUOUS BRAKE}

Common continuous brake methods include engine brake, exhaust brake, JieKebo brake, eddy current retarder, hydrodynamic retarder, etc. [7-10]. As compared to others, engine brake is easy to operate and is cost effective. Other assisted components are not required for engine brake. Hence, engine brake is widely used as a continuous method.

*Address correspondence to this author at the School of Automobile, Chang'an University, Chang'an Road, Postcard: 710064, Xi'an, China; Tel: 13572219879; E-mail: zhaoxuan@chd.edu.cn
Engine brake is a term used when the gas pedal is released, supply of fuel is cut off, clutches meet each other and the transmission is not in neutral gear. . Brake effect is generated by compression resistance, internal friction, air intake and exhaust resistance on driving wheels at the engine compression stroke.

3. BRAKE TEMPERATURE RISE MODEL OF HEAVY DUTY TRUCK RUNNING DOWNHILL

\subsection{Brake Temperature Rise Model}

When a vehicle runs on a downhill road and braking measurements are taken, the vehicle decelerates with service brake force, rolling resistance, air resistance, and continuous brake force. The stress analysis figure for vehicle braking on downhill road is shown in Fig. (1). When brake measures are taken on a downhill road, not only altitude and vehicle speed decelerate but also gravitational energy and kinetic energy decrease. The energy translates into thermal energy of service brake due to the work of rolling resistance, air resistance, and continuous brake force [11].

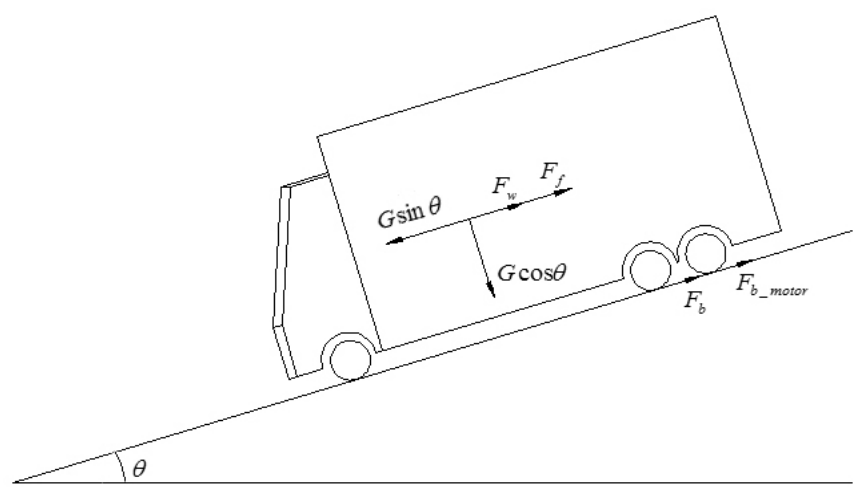

Fig. (1). Stress analysis for vehicle when downhill drive.

According to the work and energy principle in the vehicle brake process, kinetic energy and gravitational energy translate into the energy consumed by service brake, rolling 
resistance, air resistance and continuous brake force. That is to say,

$$
\frac{1}{2} m\left(u_{t}^{2}-u_{0}^{2}\right)+m g s \sin \theta=\left(F_{b}+F_{f}+F_{w}+F_{b_{-} m o t o r}\right) s
$$

where, the symbol $u_{t}$ is the final velocity, $u_{0}$ is the initial velocity, $m$ is the vehicle mass, $F_{b}$ is the service brake force, $F_{f}$ is the rolling resistance, $F_{\mathrm{w}}$ is the air resistance, $F_{b_{-} \text {motor }}$ is the engine brake force, $\theta$ is the gradient and $s$ is the driving distance.

According to energy fundamental, brake temperature rise model was built as follows,

$$
\begin{aligned}
T_{+}= & T_{0}+\frac{0.95 \cdot \varepsilon}{m_{g} \cdot c_{g} \cdot n}\left(\frac{1}{2} m\left(u_{t}^{2}-u_{0}^{2}\right)\right. \\
& \left.+m g s \sin \theta-\left(F_{f}+F_{w}+F_{b_{-} m o t o r}\right) s\right)
\end{aligned}
$$

where, $T_{0}$ is the initial temperature, $m_{g}$ is brake drum mass, $c_{g}$ is brake drum specific heat capacity, $\varepsilon$ is correction factor, which is related to axle load and the gap between brake shoe and brake drum.

\subsection{Brake Temperature Fall Model}

According to thermodynamic theory, the ways for cooling are heat conduction, heat convection and thermal radiation [12]. Among them, heat convection plays an important role while the effect of heat conduction and thermal radiation can be ignored in the process of braking. Heat convection is further explained when fluid goes over the solid surface and if temperature is variant heat transfer takes place between fluid and the solid surface. According to Newton cooling formula, brake drum temperature falls due to radiating of the surrounding air [13], Heat flux of heat convection can be calculated with equation (3),

$P_{\mathrm{d}}=h_{r} \cdot A_{2} \cdot\left(T-T_{a}\right)$

where, $h_{r}$ is strength coefficient for heat convection between brake drum and air, $T$ is brake drum temperature, $T_{a}$ is the average temperature around brake drum, $A_{2}$ is the area of extended surface for brake drum.

Formula (4) is made according to energy conservation of brake drum temperature fall [14].

$\mathrm{m}_{g} \cdot c_{g} \cdot \Delta T=-P_{-} \cdot \Delta t$

Based on equation (4), the mathematical model of brake drum temperature fall is established.

$T_{-}=\left(T_{0}-T_{\mathrm{a}}\right) e^{-A t}+T_{a}$

where, A can be calculated as follows,

$$
A=\frac{\left(5.224+1.5525 \cdot u_{a} \cdot e^{-0.0027785 u_{a}}\right) \cdot A_{2}}{\mathrm{~m}_{g} \cdot c_{g}}
$$

\subsection{Establishment of Brake Temperature Rise Model for Heavy Duty Truck Running Downhill}

Brake temperature changes include the process of brake temperature rise and brake temperature fall. According to equation (2) and (5), the model of brake temperature rise when vehicle running downhill is as follows.

$$
\begin{aligned}
T & =T_{0}+T_{+}-T_{-} \\
& =2 T_{0}+\frac{0.95 \cdot \varepsilon}{m_{g} \cdot c_{g} \cdot n}\left(\frac{1}{2} m\left(u_{t}^{2}-u_{0}^{2}\right)+m g s \sin \theta-\left(F_{f}+F_{w}\right) s\right. \\
& \left.-F_{b_{-} \text {motor }} s\right)-\left(\left(T_{0}-T_{a}\right) e^{-A t}+T_{a}\right)
\end{aligned}
$$

The function relation between engine braking torque and vehicle speed obtained from experiment is formulated as equation (7), and the value of $D_{1}, E_{1}, F_{1}$ is shown in the following Table $\mathbf{1}$.

$$
T_{b_{-} \text {motor }}=D_{1} \cdot u_{a}^{2}+E_{1} \cdot u_{a}+F_{1}
$$

Table 1. Coefficient of function relation between engine braking torque and vehicle speed.

\begin{tabular}{|c|c|c|c|c|}
\hline Gear Position & $\mathbf{1}^{\text {st }} \mathbf{G e a r}$ & $\mathbf{2}^{\text {nd }} \mathbf{G e a r}$ & $\mathbf{3}^{\text {rd }} \mathbf{G e a r}$ & $\mathbf{4}^{\text {th }} \mathbf{G e a r}$ \\
\hline \hline$D_{1}$ & -274.706 & -129.296 & -60.705 & -29.022 \\
\hline$E_{1}$ & 5090.029 & 3077.056 & 1855.535 & 1130.805 \\
\hline$F_{1}$ & 9916.007 & 7381.033 & 5402.058 & 3894.267 \\
\hline Gear Position & $\mathbf{5}^{\text {th }} \mathbf{G e a r}$ & $\mathbf{6}^{\text {th }} \mathbf{G e a r}$ & $\mathbf{7}^{\text {th }} \mathbf{G e a r}$ & $\mathbf{8}^{\text {th }} \mathbf{G e a r}$ \\
\hline \hline$D_{1}$ & -13.178 & -5.961 & -2.514 & -0.885 \\
\hline$E_{1}$ & 703.552 & 432.850 & 267.034 & 166.423 \\
\hline$F_{1}$ & 9148.591 & 8225.069 & 7499.445 & 6934.023 \\
\hline Gear Position & $\mathbf{9}^{\text {th }} \mathbf{G e a r}$ & $\mathbf{1 0}{ }^{\text {th }} \mathbf{G e a r}$ & $\mathbf{1 1} 1^{\text {th }} \mathbf{G e a r}$ & $\mathbf{1 2}{ }^{\text {th }} \mathbf{G e a r}$ \\
\hline \hline$D_{1}$ & -0.855 & -0.497 & -0.327 & -0.245 \\
\hline$E_{1}$ & 90.101 & 53.530 & 31.321 & 17.697 \\
\hline$F_{1}$ & 58.824 & -280.429 & -544.293 & -751.614 \\
\hline
\end{tabular}

The function relation between the sum of rolling resistance, air resistance and vehicle speed obtained from experiment is shown as equation (8)

$$
F_{f}+F_{w}=0.371 u_{a}^{2}+7.503 u_{a}+3216.143
$$

Based on equation (6), (7) and (8), the brake temperature rise model is,

$$
\begin{aligned}
& T=2 T_{0}+\frac{0.95 \cdot \varepsilon}{m_{g} \cdot c_{g} \cdot n}\left\{\frac{1}{2} m\left(u_{t}^{2}-u_{0}^{2}\right)+m g \mathrm{~s} \frac{i}{\sqrt{1+i^{2}}}\right. \\
& \left.-\left[\left(0.371+D_{1}\right) \cdot u_{a}^{2}+\left(7.503+E_{1}\right) \cdot u_{a}+\left(3216.143+F_{1}\right)\right] \cdot \mathrm{s}\right\} \\
& -\left(T_{0}-T_{\mathrm{a}}\right) e^{-A t}-T_{a}
\end{aligned}
$$




\section{SIMULATION RESEARCH FOR HEAVY DUTY TRUCK RUNNING ON CONTINUOUS DOWNHILL ROAD}

\subsection{Parameters for Simulation Model}

Driving performance on continuous downhill road is tested with Dongfeng Tianlong DRL4251A9 truck, which is considered as a simulation object. Simulation parameters of the tested vehicle are shown in Table 2.

Table 2. Simulation parameters of the test vehicle.

\begin{tabular}{|c|c|c|c|}
\hline Parameters & Symbol & Unit & Value \\
\hline \hline Vehicle mass & $m$ & $k g$ & 56000 \\
\hline Brake number & $n$ & $m$ & 12 \\
\hline Brake radius & $r_{g 1}$ & $m$ & 0.21 \\
\hline Vehicle wheel radius & $r$ & $k g$ & 0.5377 \\
\hline Brake drum mass & $m_{g}$ & $J /\left(k g *{ }^{\circ} \mathrm{C}\right)$ & 482 \\
\hline $\begin{array}{c}\text { Brake drum specific } \\
\text { heat capacity }\end{array}$ & $c_{g}$ & $m^{2}$ & 0.39 \\
\hline Brake drum area & $A_{2}$ & & 4.1 \\
\hline Transmission ratio & $i_{0}$ & & 0.89 \\
\hline $\begin{array}{c}\text { Transmission } \\
\text { efficiency }\end{array}$ & $\eta_{t}$ & & \\
\hline
\end{tabular}

\subsection{Simulation Results}

Brake temperature rise model of heavy duty truck running on continuous downhill road is studied with particular focus on different brake methods, gear position, vehicle speed and gradient. Downhill road distance is used as index of downhill driving performance when the temperature of brake rises to $250^{\circ} \mathrm{C}$. Comparisons are made between the usage of service brake only and the usage of combined brake, which includes engine brake and service brake. Similarly, driving performance on downhill road at 9th gear and $10^{\text {th }}$ gear is also thoroughly compared with different vehicle speed and diverse gradient..

In the simulation process, it is assumed that initial temperature of brake is $30^{\circ} \mathrm{C}$, and the temperature around brake is $35^{\circ} \mathrm{C}$. The mathematical value of brake temperature is obtained with different vehicle speed, gear position, brake method and gradient.

(1) Brake temperature rise simulation result under the circumstance of the application of engine brake and service brake at 9 th gear, is $50 \mathrm{~km} / \mathrm{h}$.

Brake temperature rise simulation result under the circumstance of the application of engine brake and service brake combination at 9 th gear, is $60 \mathrm{~km} / \mathrm{h}$.

Brake temperature rise simulation result under the circumstance of the application of engine brake and service brake combination at $10^{\text {th }}$ gear, is $50 \mathrm{~km} / \mathrm{h}$.

Brake temperature rise simulation result under the circumstance of the application of service brake only at $10^{\text {th }}$ gear, is $50 \mathrm{~km} / \mathrm{h}$.

\subsection{Contrastive Analysis of Simulation Results}

According to Figs. (2, 3), if engine brake and service brake are applied together, vehicle travels on $5 \%$ downhill road in the 9 th gear is at $50 \mathrm{~km} / \mathrm{h}$. When the brake temperature rises to $250^{\circ} \mathrm{C}$ and driving distance reaches $8055.56 \mathrm{~m}$. Vehicle runs on $5 \%$ downhill road is at the speed of $60 \mathrm{~km} / \mathrm{h}$ and the distance reaches $8516.67 \mathrm{~m}$.

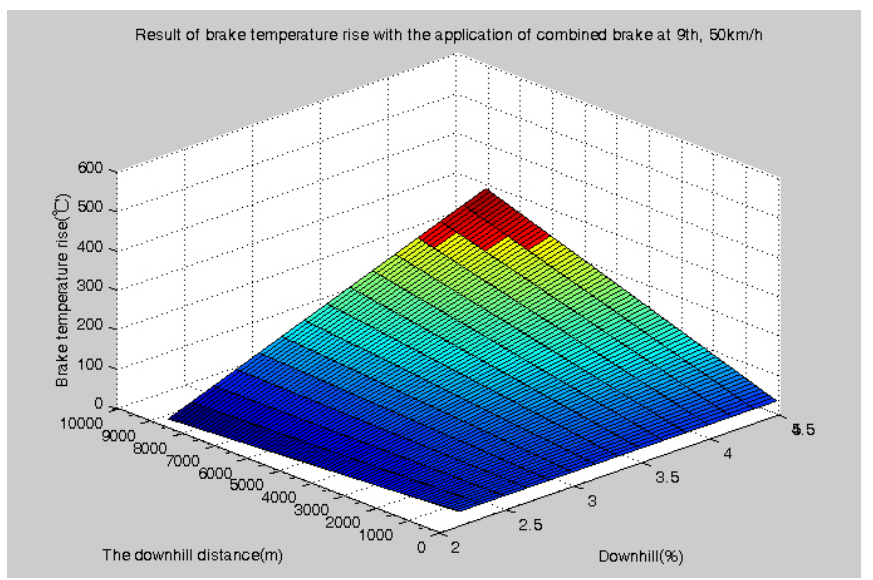

Fig. (2). Result of brake temperature rise with the application of combined brake at 9 th, $50 \mathrm{~km} / \mathrm{h}$.

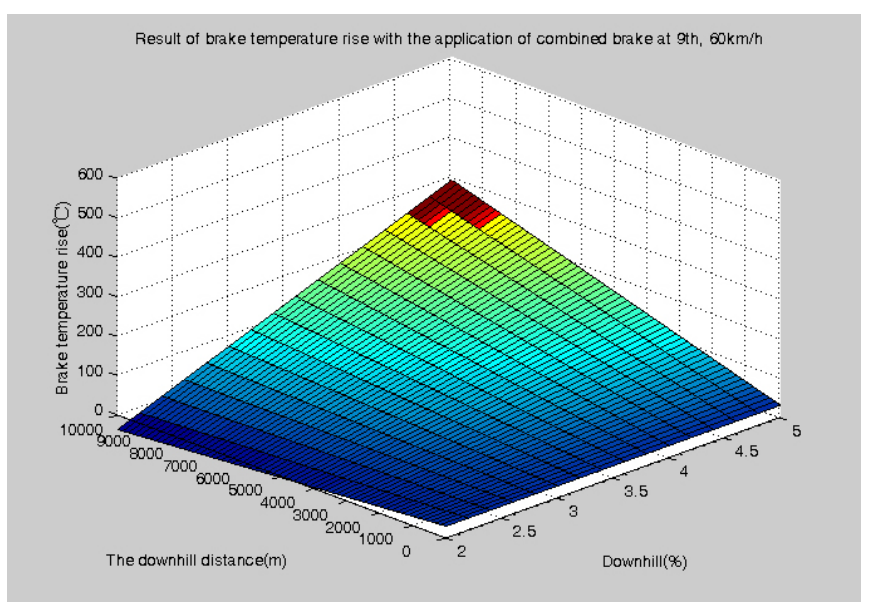

Fig. (3). Result of brake temperature rise with the application of combined brake at $9 \mathrm{th}, 60 \mathrm{~km} / \mathrm{h}$.

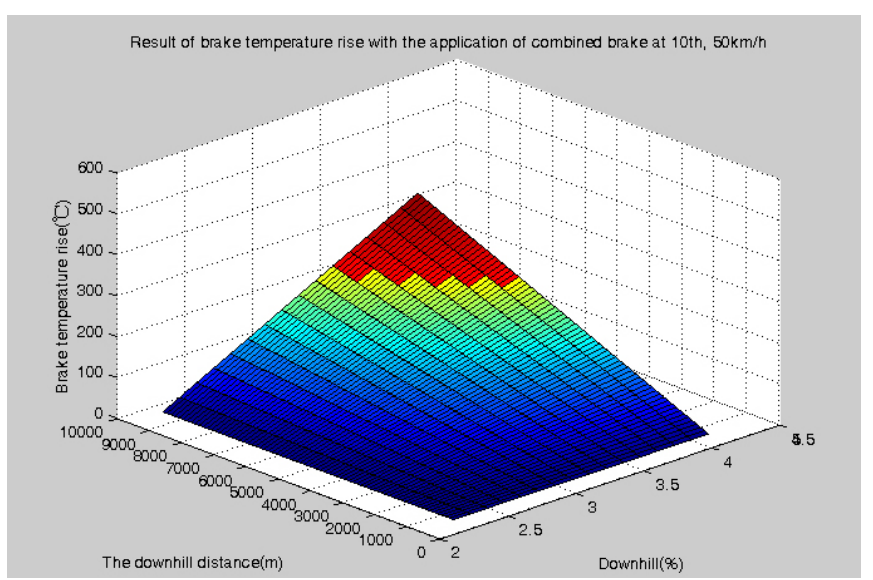

Fig. (4). Result of brake temperature rise with the application of combined brake at $10^{\text {th }}, 50 \mathrm{~km} / \mathrm{h}$. 
(2) According to Figs. $(2,4)$, if engine brake and service brake are applied together, vehicle runs on $5 \%$ downhill road in the 9 th gear is at $50 \mathrm{~km} / \mathrm{h}$. When the brake temperature rises to $250^{\circ} \mathrm{C}$ driving distance reaches $8055.56 \mathrm{~m}$. Vehicle runs on $5^{\circ}$ downhill road in the $10^{\text {th }}$ gear at $50 \mathrm{~km} / \mathrm{h}$ the distance reaches $6805.56 \mathrm{~m}$.

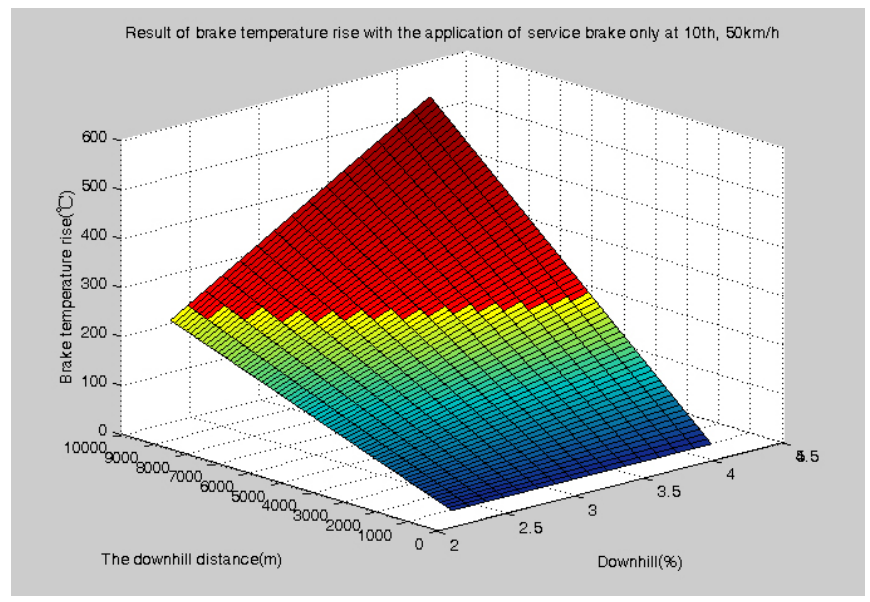

Fig. (5). Result of brake temperature rise with the application of service brake only at $10^{\text {th }}, 50 \mathrm{~km} / \mathrm{h}$.

According to Figs. $(\mathbf{4}, \mathbf{5})$, if engine brake and service brake are applied together, vehicle runs on $5 \%$ downhill road in the $10^{\text {th }}$ gear is at $50 \mathrm{~km} / \mathrm{h}$. When the brake temperature rises to $250^{\circ} \mathrm{C}$ the driving distance reaches $6805.56 \mathrm{~m}$. If service brake is applied only, vehicle runs on $5 \%$ downhill road in the $10^{\text {th }}$ gear is at $50 \mathrm{~km} / \mathrm{h}$ and the distance reaches $5972.22 \mathrm{~m}$.

(4) According to Fig. (4), if engine brake and service brake are applied together, vehicle runs on $3 \%$ downhill road in the $10^{\text {th }}$ gear is at $50 \mathrm{~km} / \mathrm{h}$. When the brake temperature rises to $250^{\circ} \mathrm{C}$ driving distance reaches $20555.56 \mathrm{~m}$. similarly, when vehicle runs on $4 \%$ downhill road the distance reaches 10138.89 mand vehicle runs on $5 \%$ downhill road the distance reaches $6805.56 \mathrm{~m}$.

(5) According to Fig. (5), if service brake is applied only, vehicle runs on $3 \%$ downhill road in the $10^{\text {th }}$ gear is at $50 \mathrm{~km} / \mathrm{h}$. When the brake temperature rises to $250^{\circ} \mathrm{C}$, driving distance reaches $14583.33 \mathrm{~m}$. When vehicle runs on $4 \%$ downhill road the distance reaches $8472.22 \mathrm{~m}$. in the same way, when vehicle runs on $5 \%$ downhill road the distance reaches $5972.22 \mathrm{~m}$.

\section{CONCLUSION}

Focussing on safety problem of heavy duty vehicle running on continuous downhill road, the model of combination of engine brake and service brake is ivestigated and analyzed. The brake temperature rise model is constructed, and then brake temperature rise and downhill distance is studied with variant vehicle speed, gear position, brake method and gradient. Conclusions are made as follows through comparative analysis of simulation results.

(1) When combined brake is applied under the circumstance of same gradient and vehicle speed and higher gear position is chosen, then continuous brake force is less . Likewise, the speed of brake temperature rise is also fast and downhill distance remains short. If lower gear position is chosen, then continuous brake force is high. In the same way, the speed of brake temperature rise is slow and downhill distanceremains long.

When combined brake is applied under the circumstance of same gradient and gear position, and the vehicle speed is low, then continuous brake force is also less. Likewise the speed of brake temperature rise is also fast and downhill distance remains short. If the vehicle speed is high, then continuous brake force is also high. The speed of brake temperature rise is slow and downhill distance remains long.

If combined brake is applied Under the circumstance of same gradient, vehicle speed and gear position, the speed of brake temperature rise remains slow and downhill distance remains long. If service brake is applied only, the speed of brake temperature rise is fast and downhill distance remains short.

Under the circumstance of same brake method, vehicle speed and gear position, the speed of brake temperature rise is fast and the downhill distance remains short if the gradient is large.

As a result, combined brake method should be chosen for heavy duty vehicle when it runs on continuous downhill road at low gear position and high speed.

\section{CONFLICT OF INTEREST}

The authors confirm that this article content has no conflict of interest.

\section{ACKNOWLEDGEMENTS}

This paper belongs to the project of the "Chang'an University-The Central College Funds", No.2013G1221027, Research on Control Strategy of Composite Braking of Pure Electric Bus Based on Multi-objective Programming Theory and Implementation; and the project of "Xi'an Science and Technology Plan Project", No. CX12162, Study on Comprehensive Technology of Heavy Commercial Vehicle Safety Guarantee and the project of "Chang'an UniversityThe Central College Funds", No. 2013G3224020, Study on Comprehensive Technology of Heavy Commercial Vehicle Downhill Safety Guarantee.

\section{REFERENCES}

[1] Study of Traffic Safety Facility System in Dangerous Sections of Mountain Expressway. Western China Communications Science \& Technology, vol. 10, pp. 4-11, 2012.

[2] H. Wang,X. Sun, and Y. He, "The relationship between trailing crash and road alignment in mountain areas", Journal of Beijing University of Technology, vol. 36, no. 9, pp. 1236-41, 2010.

[3] L. Ma, Y. Zhou, and Y. Yang, "Occurrence probability prediction model of brake malfunction on a succession of downhill highways in mountainous regions", Transport Standardization, vol. 208, pp. 80-83, 2009.

[4] Y. Cheng, "The method of speed designing for entrance of continuous downhill hedge lane", Journal of China \& Foreign Highway, vol. 33, no. 1, pp. 298-9, 2013.

[5] X. Zhang, J. Gao, and L. Kong, "Driving safety on continuous downhill expressway", Shan Dong Communications Science \& Technology, vol. 6, no. 44, pp. 17-19, 2006. 
[6] D.K. Whiteford, NCHRP Synthesis 178. Truck Escape Ramps. A synthesis of highway practice. Transportation Research Board, vol. $5,1992$.

[7] R. Xiao, Y. Ye, X. Zhou, and D. Liu, "Critical slope length computation of engine brake inefficacy", Journal of Traffic and Transportation Engineering, vol. 6, no. 4, 122-6, 2006.

[8] Q. Yu, Y. Chen, J. Ma, R. Guo, and Y. Zhang, "Research on engine brake performance of passenger car", Journal of Xi'an Highway University, vol. 19, no. 4, pp. 90-92, 1999.

[9] C. Hu, J. Shen, and Y. Chen, "Temperature-rising Laws of Drum brake pad for truck on long downgrades", Journal of Traffic and Transportation Engineering, vol. 9, no. 44, pp. 49-55, 2009.

[10] R. Xiao, X. Zhou, and Y. Ye, "Calculation of criticalvalue for downhill road driving distance of vehicle brake failing with exhaust brake applied", Journal of Safety and Environment, vol. 7, no. 6, pp. 107-9, 2007.

[11] J.Jancirani, S.Chandrasekaran, and P.Tamilporai, "Design and heat transfer analysis of automotive disc brakes Conference", American: American Society of Mechanical Engineers, vol. 4, no. 1, pp. 6569, 1993.

[12] X. Mou, Vehicle Theory. Chongqing, Chongqing University Press, 1987, pp. 89-101.

[13] S. Jin, and B. Du, "Prediction model ofbrake temperature oftruck on long and steep downgrade" Journal of Highway and Transportation Research and Development, vol. 28, no. 2, pp. 1336, 2011.

[14] A.J.Day, "The dissipation of frictional energy from the interface of an annular disc brake", Proceedings of the Institution of Mechanical Engineers, vol. 198, no. 11, pp. 201-9, 1984.

Received: September 10, 2014

Revised: November 5, 2014

Accepted: November 5, 2014

(C) Zhaoet al.; Licensee Bentham Open.

This is an open access article licensed under the terms of the Creative Commons Attribution Non-Commercial License (http://creativecommons.org/licenses/ by-nc/4.0/) which permits unrestricted, non-commercial use, distribution and reproduction in any medium, provided the work is properly cited. 